\title{
Muta-soud: Architectural Configuration Generated from Music and Shape Grammars
}

\author{
Daniella Alves Leal \\ Universidade Federal do Mato Grosso do Sul | Brazil | alvesdani088@gmail.com \\ Gilfranco Medeiros Alves \\ Universidade Federal do Mato Grosso do Sul | Brazil | gilfranco.alves@ufms.com
}

\begin{abstract}
This paper proposes a design experiment that mixes music and architecture, through Shape Grammars. Each form and initial rule had musical markers that represented them and with the development of the application of the various rules, they became formal scores. After analyzing the functionality and studying volumetries, in order to give three-dimensional movement to the various results generated (botton-up), through adjustments that depend on individual and intuitive decisions (top-down), the resulting final object is a music school destined for the propagation of music, in a way, producing a metaphor of itself.
\end{abstract}

Keywords: Music; Shape Grammars; Generative Process; Materialized Sound; Computer Design.

\section{INTRODUÇÃO}

A prática arquitetônica expandiu-se muito nas últimas décadas, especialmente em função da revisão dos modos de vida contemporâneos, e de computadores e programas que desenvolveram mudanças significativas no que diz respeito ao relacionamento e à comunicação entre os seres humanos, através da mediação digital. Percebe-se que o campo da Arquitetura vem se transformando, alimentado por pesquisas desenvolvidas no campo da interação cibernética, que envolve a comunicação entre seres humanos e máquinas, e que vem modificando rapidamente os processos de projeto, seja do ponto de vista das técnicas, quanto dos métodos. Em relação aos métodos, as Gramáticas da Forma (Shape Grammars), fazem parte desses processos de mediações possíveis. Knight (2003) define que as Gramáticas da Forma, as quais possibilitam gerar linguagens de projetos, têm sido usadas amplamente ao longo dos últimos anos para descrever e compreender a diversidade de estilos arquitetônicos e outros tipos de projetos. De acordo com a autora, estas gramáticas foram desenvolvidas para abordar duas questões fundamentais no projeto: a análise de estilos contemporâneos ou históricos de projetos, e a síntese ou a criação de estilos completamente novos e originais de projetos.

\section{METODOLOGIA E BREVE CONTEXTUALIZAÇÃO DO PROCESSO}

A revisão bibliográfica foi o primeiro passo para explorar o tema que mais tarde deu suporte para o objetivo do processo de projeto aqui proposto. A fundamentação teórica, iniciou-se por aspectos relevantes da música para a humanidade e como ela afeta as pessoas individualmente, fazendo parte da identidade cultural de cada lugar e representando historicamente sociedades desde os tempos mais remotos. Foi possível perceber que a música faz parte da expressão dos estados de espírito individuais e acompanha o ser humano em seu cotidiano, seja em forma de sons indiretos ou estruturada na expressão artística. Seguiu-se com uma pesquisa sobre como a música é representada por meio de signos gráficos, e na sequência, um estudo sobre as intersecções possíveis entre arquitetura e música. Os objetos gráficos de representação dos sons e da música, não se reduzem apenas aos signos da notação musical, mas, por meio de expressões sinestésicas ou baseadas em outros critérios, a música pode ser também significada por cores, formas geométricas, colagens, espectros, recortes e expressões corporais, dentre outros. Com o surgimento dos meios digitais, representações computacionais dos sons também vêm sendo utilizados para criar outros tipos de partituras que ao serem executadas, expressam uma nova versão da música. $\mathrm{E}$ os processos generativos fazem parte dessa tentativa de alcançar novas esferas do campo projetual. Um exemplo disso foi estudado por Fornari \& Maya (2011), que explicam que além do tipo de notação musical tradicional, também existem as partituras de escuta visual que foram criadas na década de 1970 por Rainer Wehinger. Esse tipo de partitura foi criado especialmente para a peça Artikulation de György Ligeti. Os artistas de música computacional na primeira década do século XXI utilizam modelos computacionais para criar essas representações de peças musicais.

Percebendo que essas conexões poderiam ser feitas e analisando as possibilidades metodológicas disponíveis em função das tecnologias digitais aplicadas aos processos de projeto em arquitetura, os princípios da Gramática da Forma foram os escolhidos para interpretar a linguagem musical no processo computacional interativo experimental tratado nesse artigo.

As Gramáticas da Forma permitem que, de forma interativa a visualização dos vários resultados, torne o poder de escolha do profissional projetista mais abrangente. Carneiro (2014), revendo os princípios de interação apontados por Dubberly, Haque e Pangaro (2009) trata diretamente da capacidade de explorar a arquitetura e o processamento digital. Alterando os modos de trabalho significativamente, aos poucos o computador passou a 
influenciar o pensamento e a produção de espaços. Assim, a arquitetura interativa e a tecnologia digital possibilitam a implementação de interações viabilizadas pelos processadores inseridos em sua estrutura. Segundo Carneiro (2014), falar sobre arquitetura interativa significa, referir-se a comportamentos programados para serem implementados. Sendo assim a possibilidade do design a partir de estratégias, conceitos, lógicas e raciocínios, se diferem daqueles mais intuitivos, presentes nos processos mais tradicionais de concepção de projeto de arquitetura.

Como sabemos, as Gramáticas da Forma são um sistema de geração de formas baseado em regras que surgiu a partir dos estudos teóricos de Noam Chomsky (1956) e do sistema de produção do matemático Emil Post (1943), que substituía caracteres em uma sequência de letras com o objetivo de gerar outras novas sequencias. Chomsky, desenvolvendo esse método nos anos 50, definia um conjunto de regras cujas combinações podiam gerar todas as frases em uma linguagem, a partir de um símbolo definido inicialmente. Stiny e Gips, propuseram o uso de formas geométricas e de transformações euclidianas, ao invés de símbolos matemáticos, e da substituição de caracteres. Mendes (2018) cita que Stiny e Gips, idealizadores das bases da Gramáticas da Forma, utilizavam-se inicialmente da translação, rotação, espelhamento e roto-translação, que permitiam adição e subtração de formas, assim modificando sua escala e dando novos rumos à teoria. Ou seja, enquanto Chomsky definia um alfabeto de símbolos, as Gramáticas da Forma a partir de um alfabeto de formas, geraria uma linguagem de formas. Sabendo desses critérios, é possível então considerar que a linguagem é um dos fatores mais importantes do processo, e que ela pode ser estabelecida por símbolos ou formas iniciais que ao serem alterados proporcionaria resultados diferentes. Os símbolos iniciais escolhidos nessa pesquisa são resultados da combinação entre formas e elementos musicais, gerando frases musicais formais capazes de serem lidas e interpretadas musicalmente, mas também, como consequência, espacialmente ocupadas por usuários.

Os principais procedimentos metodológicos relacionados ao processo de projeto após a pesquisa de revisão bibliográfica e as considerações sobre a transformação de objetos sonoros em objetos gráficos, ocorreram da seguinte maneira: passo 1: notas musicais foram usadas como marcadores de formas do tipo top-down, que por meio de regras de Gramática da Forma geraram representações assemelhadas à uma partitura formal. 2: tais partituras foram geradas a partir de regras que mudavam as composições finais, com uma estratégia do tipo botton-up. 3: as formas geraram combinações que podiam ser interpretadas por um instrumento musical, no caso, foi utilizado um teclado. 4: em função do recorte e da natureza do projeto, foi escolhida uma única forma para o desenvolvimento do objeto arquitetônico final. 5. através de ajustes que dependem de decisões individuais e intuitivas (top-down), o objeto final resultante é uma escola de música destinada ao ensino e ao fomento da música, de certo modo, produzindo uma metáfora de si mesmo.

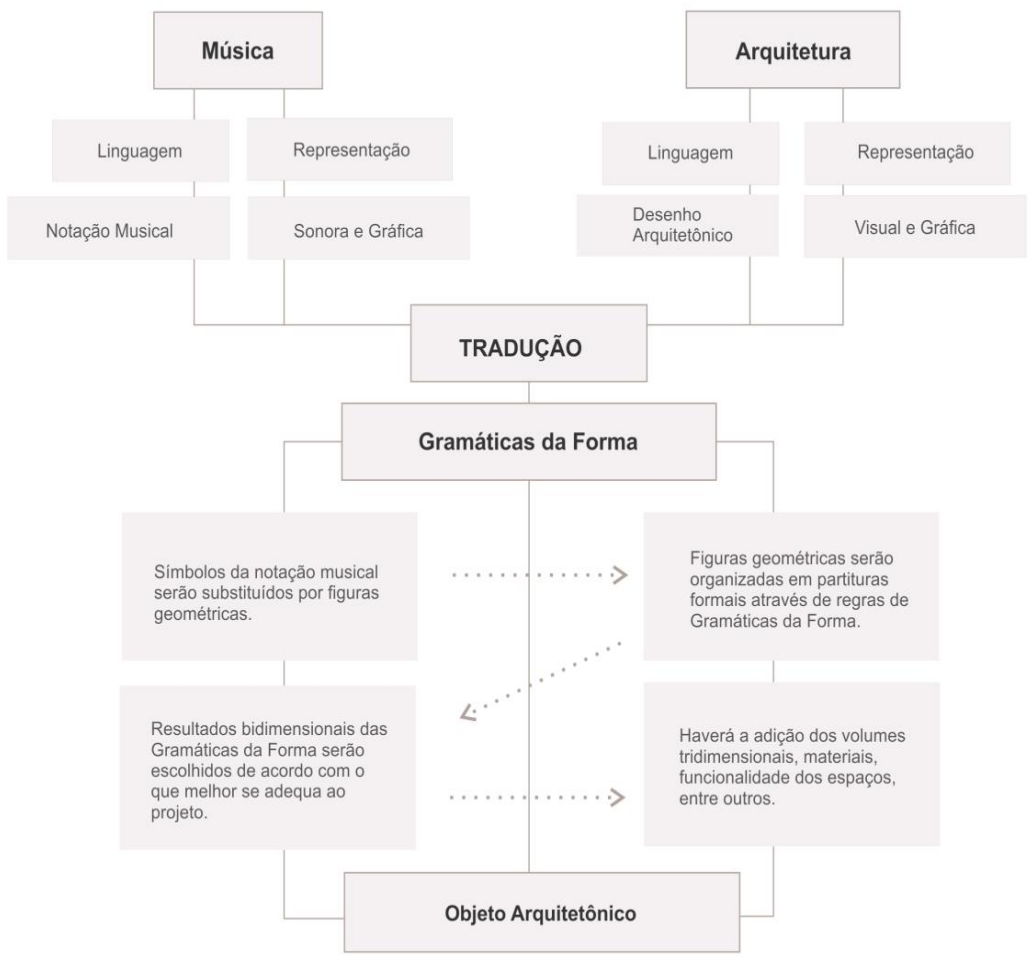

Figura 1: Diagrama dos processos. Fonte: autores 2020. 


\section{PROCESSOS DE CONCEPÇÃO INICIAIS}

Sabendo que as Gramáticas da Forma seriam a base da tradução entre música e forma, foi preciso criar um código musical que se encaixasse no processo a partir de iniciativas individuais. $O$ código criado foi baseado em uma série de decisões que melhor atenderia ao objetivo final.

Considerando que o produto a ser gerado era de natureza arquitetônica, foi preciso estabelecer alguns critérios básicos que poderiam ser transformados em espaços físicos posteriormente. O primeiro recurso que significou o espaço foi seu pré-dimensionamento. Utilizando medidas maiores que $36 \mathrm{~m}^{2}$ e menores que $144 \mathrm{~m}^{2}$ como base, com alguns acréscimos e reduções dependendo do tipo de forma, foram esboçadas manualmente as primeiras geometrias em uma iniciativa do tipo top-down, que poderiam ser circulares, retangulares, triangulares ou uma mescla. Considerou-se também, que os espaços gerados por essas formas seriam usados como salas de aula no futuro, e por isso as medidas deveriam ser satisfatórias para atender a função, independentemente da configuração de lay-out e mobiliário que posteriormente pudesse existir. Também foram esboçadas formas muito pequenas ou cruzamentos de linhas para significar elementos de apoio ou interesse visual como pilares, muros ou marcos da construção.

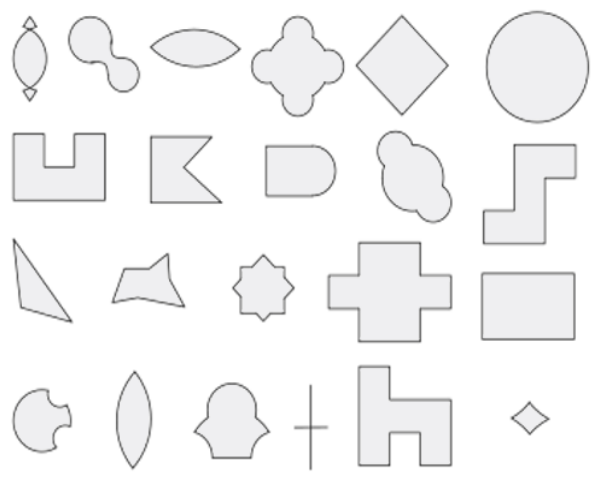

Figura 2: Exemplos dos tipos de formas utilizadas. Fonte: Autores 2020.

O segundo passo, após o esboço das primeiras formas, foi juntamente com elas definir qual recurso da música melhor representaria gramaticalmente as formas. Os elementos escolhidos foram as principais notas musicais simbolizadas por letras, e essas notas representadas por letras foram os marcadores inseridos dentro de cada figura geométrica, mudando de acordo com as regras de Gramáticas da Forma, à medida que fossem dispostas nas composições. Para cada forma diferente, foi atribuída uma nota musical, para cada regra, foi atribuída uma combinação de notas musicais a partir da primeira forma existente.

A escolha das notas musicais e como elas seriam inseridas na regra foi feita de forma arbitrária, intencionando que o som final interpretado pela junção de frases de Gramática da Forma, se transformaria em um tipo de partitura que, ao interpretada, pudesse gerar uma melodia inédita ou surpresa. Algumas notas menores e sustenidos, representadas por formas fizeram com que o tom das partituras formais finais mudasse e as melodias fossem completamente diferentes umas das outras.

Para exemplificar a aplicação, consideramos que na Forma 1 será adicionado o marcador $C$, onde $C$ representa a nota Dó. Aplicando-se a primeira regra, Regra 1, sobre a Forma 1 , teremos o resultado onde a Forma 1 será modificada por operações booleanas, euclidianas ou outras, porém não alterando sua característica principal de acordo com regras de Gramáticas da Forma. Considerando que nesse caso específico, o tipo de operação feita será a adição de um elemento, perceberemos que após a aplicação da Regra 1, a Forma 1 terá agora dois elementos, duas formas diferentes ligadas uma à outra. Na sequência, com a Regra 1 aplicada, a Forma 1 terá os marcadores $\mathrm{F}+\mathrm{C}$ onde $\mathrm{F}$ representa a nota Fá e C representa a nota Dó. Se aplicarmos a Regra 2 na Forma 1, perceberemos que nela será adicionada uma figura diferente da primeira regra, que leva outro marcador de nota musical. Então, após a aplicação da Regra 2 na Forma 1, ela terá os marcadores $\mathrm{E}+\mathrm{C}$, onde $\mathrm{E}$ representa a nota $\mathrm{Mi}$ e $\mathrm{C}$ representa a nota Dó.

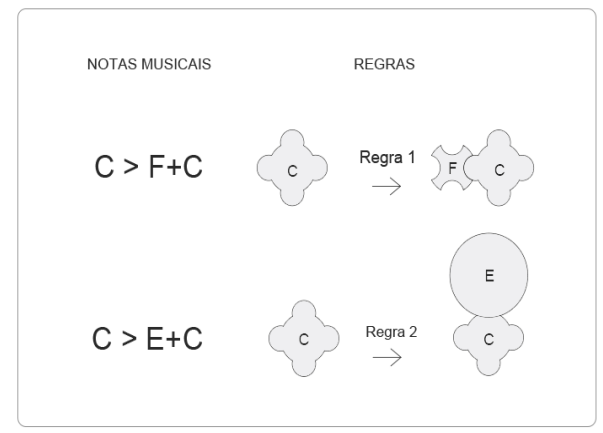

Figura 3: Exemplo de notas musicais marcando as formas. Fonte: Autores 2020.

\section{FORMA COMO PARTITURA}

Após a definição do tipo de nota musical para cada forma, e como elas mudariam em cada regra, as primeiras frases de Gramáticas da Formas surgiram. Aplicando todas as regras necessárias nas formas iniciais e esgotando as possibilidades entre a escala básica que vai de Dó a Si, por vezes experimentando notas menores e sustenidos, foi percebido e admitido um resultado do tipo botton-up, onde formavam-se uma série de composições finais. Ao final de cada composição maior de Gramáticas da Forma percebeu-se que elas também representavam um tipo de partitura formal que poderia ser executada de acordo com a posição das notas da esquerda para a direita.

As relações arquitetônicas entre as formas e a música se estabeleceram nas entrelinhas do processo, onde, de acordo com o desenrolar da execução e composição das Gramáticas, em cada forma foi inserido um símbolo sonoro, que do ponto de partida inicial até o final, definia um tipo de melodia e harmonia que se diferenciava dos outros à medida em que as composições estavam sendo criadas. O som, portanto, é parte intrínseca do processo, incluso na forma que o representa, e não um elemento físico espacial ou compositivo. Esse papel é desenvolvido pelas formas geométricas empregadas no processo. 

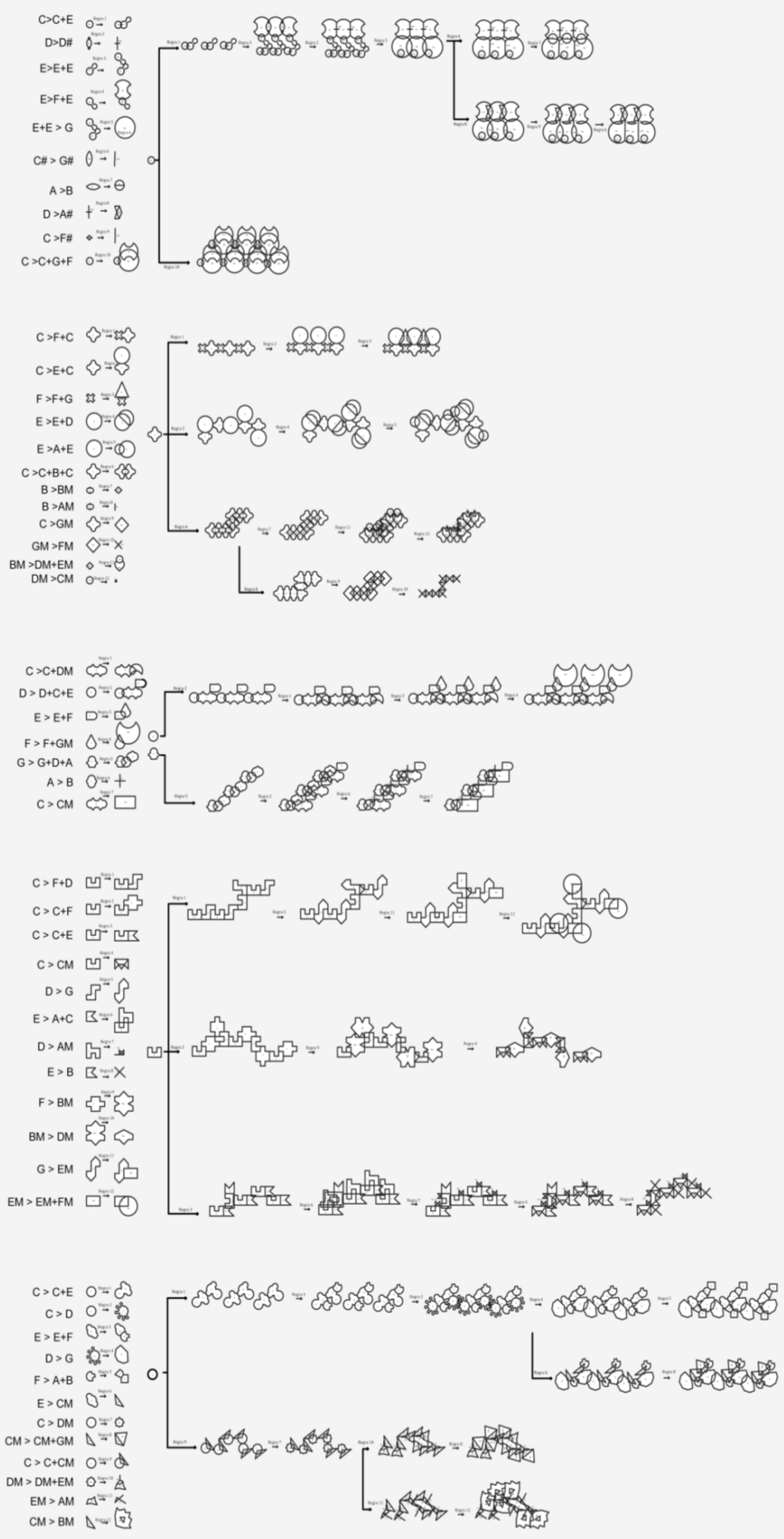

Figura 4: Composições geradas a partir de música e Gramáticas da Forma. Fonte: autores 2020. 


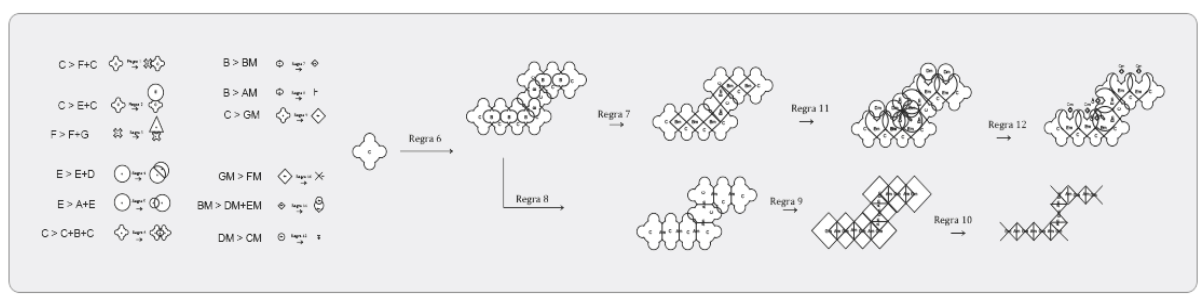

Figura 5: Recorte de um dos processos onde notas e forma se transformam em uma frase/partitura formal. Fonte: autores 2020.

Para a execução das partituras geradas pelas formas fo utilizado um teclado musical, e cada composição final gerou uma melodia diferente da outra, de acordo com a mudança das regras que foram aplicadas ao longo do processo. As melodias são a representação musical das formas, e as formas são a representação física das notas, de acordo com o desenrolar de sua disposição e elas têm papel no processo de composição como marcadores, mas elas não alteram a qualidade dos espaços ou representam um elemento físico nele, sendo esse papel feito pela evolução volumétrica dos planos bidimensionais e a adequação delas do ponto de vista funcional. Sendo assim, nas formas bidimensionais foram adicionados volumes para entender como se comportavam tridimensionalmente, já intencionando a existência de possíveis vedações e cobertura. Os principais software utilizados para esse propósito, foram primeiramente o AutoCAD para desenhar as formas bidimensionais e o Rhinoceros para a adição volumétrica.

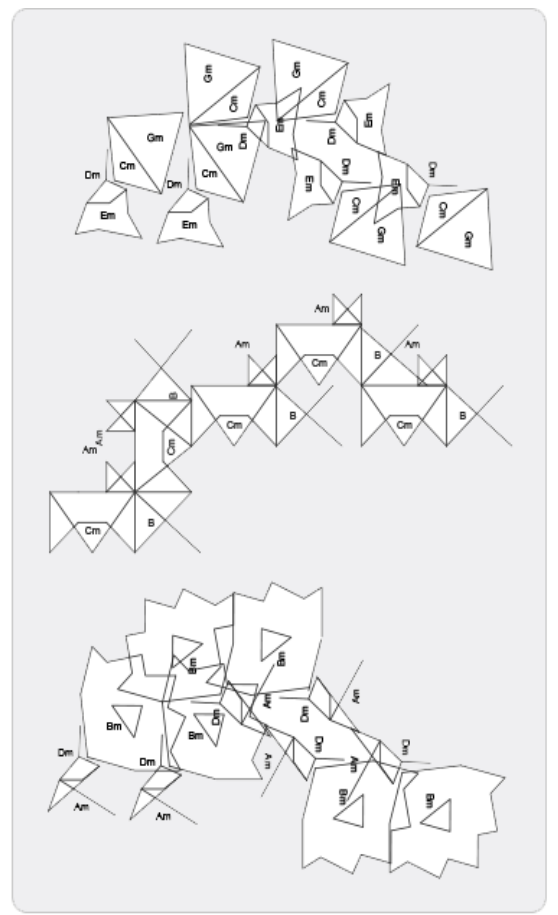

Figura 6: Exemplo de partituras formais bidimensionais, resultantes da aplicação de Gramáticas da Forma. Fonte: Autores 2020.

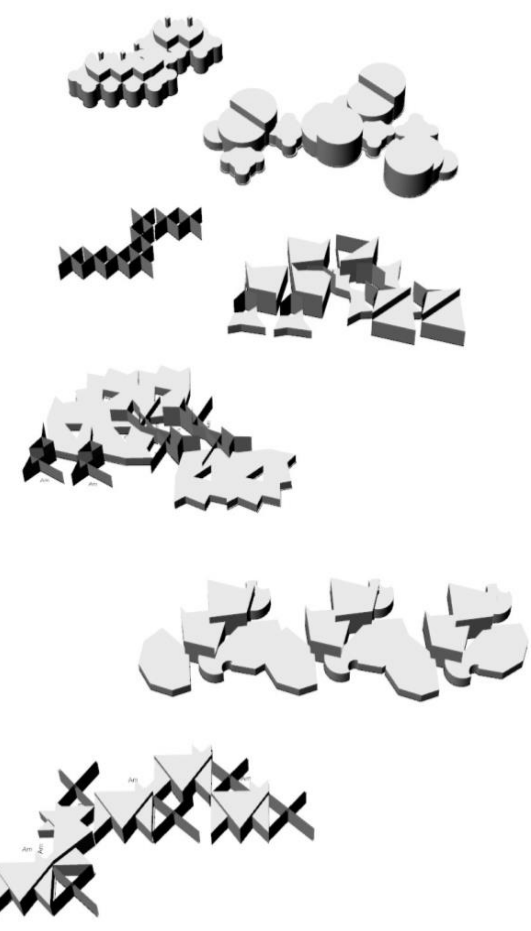

Figura 7: Exemplo de frases formais tridimensionais, resultantes da aplicação de Gramáticas da Forma. Fonte: Autores 2020.

Ao todo foram geradas 16 diferentes composições formais finais, a partir de 40 intermediárias ao longo do processo, partindo de 5 diferentes grupos de regras envolvendo diferentes arranjos e notas musicais. Nas composições finais foi preciso analisar as possibilidades, desconsiderando as formas mais estreitas e pouco interessantes para o desenvolvimento de espaços utilizáveis arquitetonicamente e fazer um recorte que compete ao projetista, escolhendo as formas bidimensionais que quando desenvolvidas tridimensionalmente, fossem mais adequadas e funcionais para o propósito do projeto final. 


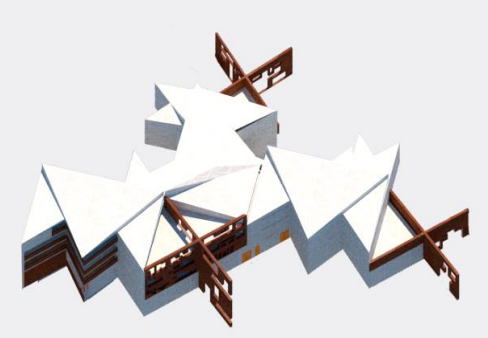

Figura 8: Maquete volumétrica da escola de música gerada por um dos resultados formais tridimensionais. Fonte: Autores 2020.

\section{RESULTADOS}

O resultado foi um objeto de arquitetura contemporânea baseado na experimentação e no processo generativo de projeto. Acredita-se que resultados apresentam a possibilidade de mapeamento do processo de projeto que utiliza Gramáticas da Forma, a partir da retroalimentação entre teoria e prática, visando modificar o paradigma do processo de projeto tradicional em contraposição ao tradicional "desafio do papel em branco". Trata-se de incentivar novos métodos através de estratégias computacionais e generativas, não com a pretensão de esgotar os temas relacionados à tradução de elementos sonoros, nem ignorar todas as outras maneiras de concepção de projeto, mas fazendo um recorte de um método específico possível como objetivo de experimentação.

Segundo Celani (2011) o processo generativo visa a otimização devido à variedade, através de múltiplas alternativas. Esse projeto é o produto de diversas alternativas tanto visuais como auditivas que procuram estabelecer através de uma escolha, a melhor opção entre elas, evitando assim apenas as primeiras opções, comumente utilizadas nos processos de projeto arquitetônico, e geralmente atreladas estritamente a questões programáticas como ponto de partida. A evolução da forma do presente projeto deu-se juntamente com os parâmetros previamente definidos, e várias possibilidades foram geradas.

Foi possível perceber também como características da música, dos sons e dos elementos musicais podem ser representados não só por símbolos tradicionais da notação musical, mas por inúmeros outros elementos gráficos dentro tanto dentro da teoria musical, quanto fora dela. 0 critério específico para essa tradução depende do profissional que aplica e como ele estabelece esses critérios de tradução de acordo com o objeto final desejado, nesse caso, utilizando as similaridades entre música e arquitetura.

O resultado do projeto arquitetônico carrega todas as características do processo de projeto. Foi primeiro escolhida uma das frases tridimensionais finais resultantes das Gramáticas da Forma e então foi feito um recorte que se adequasse a uma situação real de terreno, e considerados os resultados mais próximos de ambientes destinados ao ensino da música, com ajustes acústicos, escolha de vedação, materiais e todos os outros elementos que caracterizam um projeto arquitetônico. O projeto é resultado da mistura da música com a arquitetura, a partir das Gramática da Forma, mas também busca valorizar e experimentar a música dentro de suas formas arquitetônicas. As relações entre a música e o espaço são à primeira vista abstratas, se considerarmos 0 conhecimento do processo de projeto que foi aplicado nele, mas cada um dos espaços possui um som específico intrínseco, se executado da maneira em que os marcadores iniciais foram dispostos. $O$ design computacional torna esse processo mais abrangente e objetivo, tornando os códigos também espaços significados.

A trama tridimensional resultante das frases geradas bidimensionalmente fazem alusão a outros elementos da música, como o movimento, o ritmo, as alturas e os compassos, deixando à critério técnico do profissional resolver qual será o melhor jeito de materializar arquitetonicamente esses elementos.

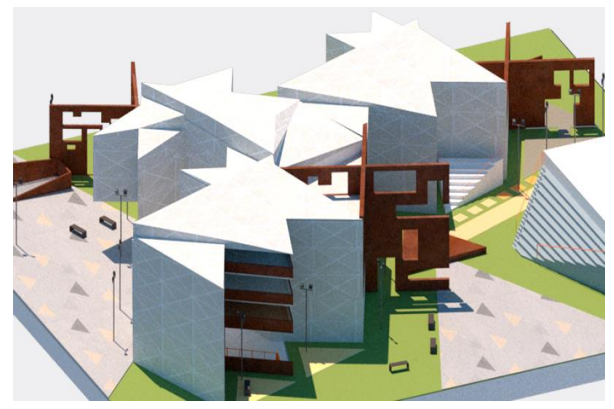

Figura 9: Maquete volumétrica da escola de música mostrando pavimentos e como foi inserida em um terreno. Fonte: Autores 2020.

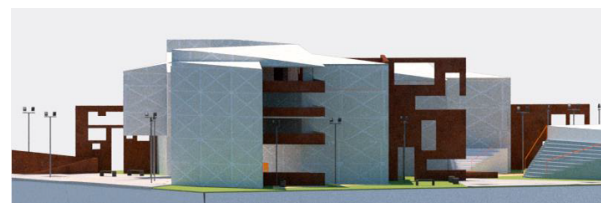

Figura 10: Vista lateral da Escola de música. Fonte: Autores 2020.

\section{DISCUSSÃO}

Pelo menos desde o sexto século a.C. a música e a arquitetura tem sido intimamente ligadas por uma conexão natural. Segundo Jenks (2013), ambas são geradas pela ordem de um código subjacente que o filósofo grego Pitágoras defendia por meio da matemática e da geometria. O templo grego sintetizou tais conexões como um tipo de edifício criado em torno da performance musical, onde a forma perfeita das pedras, refletia literalmente os sons da dança e da flauta. A arquitetura é uma arte percebida de variados ângulos, a partir de diversas distâncias e velocidades de movimento. A característica musical no espaço arquitetônico é uma propriedade explorada por diversos arquitetos, como por exemplo Peter Eisenman, que imprime esse tipo de articulação, dentre outras obras, no memorial ao holocausto feito por diversos cubos separados, diante de 
um padrão urbano abstrato de Berlim. Jenks (2013), também relembra Pérotin quando notou no ano de 1200 que as semelhanças entre o desenho arquitetônico e a notação musical eram mais comuns do que se imagina e alguns exemplos de ambos sobrevivem. Trabalhando na Notre Dame em Paris, Pérotin introduziu um sistema notacional de notas longas e curtas para que ele pudesse sinalizar ritmos básicos. A relação era para o som, Dum-ti, Dum-ti, Dum, ti, Dum, assim como para arquitetos góticos que trabalhavam com ritmos, $A, b, A, b, A, b, A$ (JENKS, 2013). Nesse momento, tanto a música, quanto a construção começam no mesmo elemento de tensão (Dum ou $A$ ). Esses ritmos são marcados de várias maneiras na nave de Notre Dame, portanto esse paralelo é inevitável

As cidades causam impressões que não são apenas proporcionadas pela visão, mas sensoriais, a depender de como o indivíduo se relaciona com seu ambiente diário. Muitas vezes o espaço físico de edifícios representa muito mais para os indivíduos de forma particular através de sons e sentidos que chegam a ele de todas as direções. Sabe-se que dentre outros meios, a água e o ar são capazes de transmitir sons, portanto, não se pode desconsiderar que a música se propaga em elementos componentes da vida humana e do seu cotidiano. Entende-se a música para além de sua notação e apreciação artística. É preciso admitir a própria relação da música com a humanidade em toda sua proporção cultural, física e social. A música é, provavelmente, a mais antiga forma de expressão, mais até que a escrita e a arte, e, portanto, os sons são capazes de materializar os estados de espírito através da expressão artística, mas também de servir como inspiração para estruturas formais. Riad (2009) fala sobre a música com inspiração para a arquitetura quando ela é tratada de forma inconsciente como uma expressão irracional. As sensações que os sons causam, podem desencadear estímulos visuais, como cor ou formas no fenômeno chamado sinestesia. Porém ainda existe a inspiração para a arquitetura causada pela expressão racional, capaz de traduzir uma forma de arte em outra, e para isso é necessário um nível de desconstrução, e entender as qualidades abstratas de uma forma para poder aplicá-las em outra.

As ações dessa pesquisa apresentam um estudo sobre as conexões entre o processo cognitivo e o computacional, mesclando estratégias do tipo botton-up e top-down durante todo o processo de geração das formas, que viessem a representar a arquitetura de modo que ficassem expressas as conexões estabelecidas entre a música e linguagem formal.

Até os dias atuais, as conexões entre objetos formais e sons vem sendo feitas não apenas com métodos tradicionais, mas também interativos. A arquitetura e a música compartilham uma linguagem impregnada de cultura, e por meio da expressão digital, pode-se atualmente alcançar novas alturas de supremacia criativa. Como contribuição, acredita-se que os resultados apresentam possibilidades de utilização do processo de Gramáticas da Forma, a partir da retroalimentação entre teoria e prática, visando modificar o paradigma do processo de projeto tradicional, desconstruindo o mito do gênio criativo (caixa-preta) e o substituindo por métodos mais abertos e transparentes.

\section{CONCLUSÃO}

As transformações nos processos de projeto e na materialização da arquitetura mudam ao longo das décadas e outros campos passaram a auxiliar esses processos. A inserção das alternativas tem papel crucial nos rumos que a arquitetura vai tomar no futuro. Atualizar a compreensão de como as sociedades caminham para as próximas décadas é fundamental para profissionais do design e da arquitetura, para que não percam a capacidade de propor e resolver problemas característicos dos processos projetuais.

A experimentação, a construção de protótipos, os testes a mesclagem entre diversas áreas aliadas ao processo de projeto, intencionam redescobrir potencialidades, mas também apontar outras soluções possíveis para a arquitetura do futuro. A facilidade de se testar e avaliar situações geradas pelos resultados dos processos interativos e computacionais expandem tais possibilidades.

As vantagens trazidas por um processo de projeto interativo proporcionam uma percepção mais abrangente dos possíveis resultados de uma primeira intenção projetual e abrem um leque de possibilidades que dependem de decisões técnicas individuais, mas que passam a considerar com o auxílio da computação e de processos, como os generativos, a melhor opção. A mediação digital propicia hoje uma gama de possibilidades para a reflexão acerca do que os profissionais (e sociedade em geral) querem para o futuro da arquitetura e das cidades. Além disso, permite também que elementos da arte, como a música, sejam inseridos no espaço participando do processo de concepção e expandindo o próprio campo da Arquitetura. A música carrega um significado essencial às aspirações humanas e ela faz parte dos espaços essenciais à construção da identidade cultural de todas as épocas, independentemente de qualquer tipo de revolução urbana, tecnológica, política, religiosa ou científica. Esse artigo considera uma maneira experimental de materializar a música e busca incentivar os processos de projeto interativos afim de gerar alternativas para arquitetura contemporânea.

Em se tratando da contemporaneidade, a tecnologia computacional, talvez seja a potência mais capaz de manipular e materializar elementos por meios interativos, transformando ideias de composição até mesmo em espaços físicos destinados ao convívio humano. Isso é muito mais facilmente aplicado atualmente do que em épocas remotas, o que abre espaço para a experimentação. Assim como a tecnologia, a música expande a criatividade, a cognição e a sociabilidade. Os paralelos a serem feitos são diversos e extrair conceitos e processos desses fatores, é fundamental.

Este artigo, entretanto, não visa excluir ou esgotar os temas relacionados à tradução de elementos sonoros para elementos formais (situação já explorada desde Pitágoras, como citado anteriormente), nem ignorar ou subestimar todas as outras maneiras de concepção de projetos arquitetônicos, mas sim fazer um recorte de um método específico, capaz de gerar inúmeras possibilidades de desenho e que leva em conta os recursos da nossa época, oferecendo aos profissionais da área e ao público em geral, alternativas de se perceber e produzir arquitetura.

\section{AGRADECIMENTOS}

Agradecemos à UFMS pelas condições oferecidas ao desenvolvimento deste trabalho. 


\section{REFERÊNCIAS}

Bennet, R. (1998). Elementos Básicos da Música. Rio de Janeiro: Jorge Zahar Ed.

Blacking, J. (1973). Quão Musical é o Homem?. Londres: Faber \& Faber.

Carneiro, G. (2014). Arquitetura interativa: contextos, fundamentos e design. São Paulo: Faculdade de Arquitetura e Urbanismo, Universidade de São Paulo.

Celani, G., Cedrez, M. (2018). Arquitetura contemporânea e automação: prática e reflexão. São Paulo: Probooks.

Dantas, D., Guimarães, C. (2013) Partituras Imagéticas: Um diálogo Poético entre Música e Imagem. Rio de Janeiro: Universidade Federal do Rio de Janeiro.

Dubberly, H., Haque, U. \& Pangaro, P. (2009) What is interaction? Are there different types?. Recuperado de: http://www.dubberly.com/articles/what-is-interaction.html.

Fornari, J., Maia, I. (2010) Notação Interativa: Um Estudo Sobre o Projeto de Criação Musical Compositor-ComputadorIntérprete. Campinas: Universidade Estadual de Campinas.

Fornari, T. (2011, Dez 6). Um Processo de Criação Computacional Interativa de Notação Musical. Recuperado de: http://www.nomads.usp.br/virus/virus06/?sec=5\&item=30\&lan $\mathrm{g}=\mathrm{pt}$

Jenks, C. (2013) Architecture becomes Music. Recuperado de: https://www.architectural- review.com/essays/viewpoints/architecture-becomesmusic/8647050.article

Knight, Terry. (2003) Computing with Emergence. Environment and Planning B: Planning and Design, volume 30, p. 125-155.

Kowaltowski, D., Moreira, D., Petreche, J. \& Fabrício, M. (2011). O Processo de Projeto em Arquitetura: da Teoria à Tecnologia. São Paulo: Oficina de Textos.

Lacerda, O. (1967). Compendio de Teoria Elementar da Música. São Paulo: Ricordi Brasileira.

Murray, S. (1997). A Afinação do Mundo. São Paulo: Editora da UNESP.

Rabelo, F. (2007) Arquitetura e Música: Interseções Polifônicas.

Goiânia: Faculdade de Arquitetura e Urbanismo, MINTER

UFRGS/UCG

Riad, M. (2009). Musical Deconstruction/Reconstruction: Visualizing Architetonic Spaces Through Music. Maryland: Escola de arquitetura, planejamento e preservação de Maryland.

Stiny, G. (1980). Introduction to Shape and Shape Grammar. In: Enviroment and Planning B: Planning and Design 7, 343-351.

Stiny, G. (1980). Kindergarten grammars: designing with Froebels building gifts. In: Enviroment and Planning B: Planning and Design 7, 409-462.

Stumpp, M. (2013). A Simetria Modular e as Villas de Andrea Palladio. Porto Alegre: UFRGS. 